\title{
Image Artifact
}

National Cancer Institute

\section{Source}

National Cancer Institute. Image Artifact. NCI Thesaurus. Code C92062.

The unacceptable distortion of an image due to signal loss that may occur during a radiologic procedure such as magnetic resonance imaging. 